\title{
On the Teaching Problems of Cellos in Higher Normal Colleges
}

\author{
Jing Yuan \\ School of Music Shaanxi Normal University \\ hunter2011@foxmail.com
}

Keywords: Higher normal colleges; Cello; Teaching problems

\begin{abstract}
As one of the elective course in higher normal colleges, elective course of instrumental music is one compulsory course for bachelor students in higher normal colleges based on the regulations of Ministry of Education with the purpose of improving students' comprehensive artistic ability and understanding as well as respecting various musical patterns so as to better adapting to the demands for musical educational talents in 21 century. However, in the teaching for cello elective courses, there are usually technical and practical problems caused by students, which requires teachers due attention and research for the problems in teaching so as to find out the reasons and only in this way, can students better learn cellos and comprehend the teaching contents. This paper mainly analyze the necessity and influence for the cello teaching in higher normal colleges and then explain for the existing problems in the cello teaching of Chinese higher normal colleges; and then proposes relevant reform measures for related problems to promote the development of cello teaching in China.
\end{abstract}

\section{Introduction}

As an infectious and expressive instrument, cello receives more and more attention. Nowadays, most art and ordinary colleges set cello majors. However, since the time that cello was brought in China is limited; there are some relevant problems for the teaching modes and application of teaching resources etc. So relevant colleges should constantly promote the active exploration for the cello teaching modes and teaching methods, change teaching concept so as to constantly realize effective teaching.

\section{Necessity and effects of cello teaching in higher normal colleges}

Necessity of cello teaching in higher normal colleges. Nowadays, with the more and more frequent communication between internal and external colleges, some first-class performance groups often bring musical shocks and joy for Chinese people, which leads to the wide recognition of western instruments and cello receives wider and wider attention from Chinese people. Since cello plays an important role in western instrument, it is widely applied. The voice of cello is gentle and soft, which is full of artistic expressiveness and infection. The performance can be divided into solo and ensemble. The voice of cello is a bit low and sad, thus being loved by many musicians. At the same time, due to the special voice of cello, it can be applied in highly rhythmic music; therefore, it is widely applied in band and can hold the low and tenor, which makes it unmatched.

With the constant pursuit for diverse living conditions and wide recognition of music, Chinese Educational Ministry has new requirements for the music teaching in normal colleges. During colleges, the teaching and learning of instruments should not be limited to the technical teaching for few students. But instead, it should expand teaching scope and ask students to take an instrument as elective course and learn. Under this condition, setting up compulsory and elective course in normal colleges is necessary. And there is some difference between the major and course setting in normal colleges and specialized musical college, it can reduce the requirements for students' techniques and stage performance and more attention should be paid to the musical interests and fundamental music. Normal college's teacher should make relevant innovations for the teaching methods and curriculum setting during teaching and avoid the direct application of the teaching system in specialized musical colleges; but instead, it should start from the demands and teaching purposes of 
itself and constant build up particular teaching modes and teaching structures to promote the teaching of cellos.

Effects of cello teaching in higher normal colleges. (1) Promote students' cognition and knowledge. Cello belongs to typical instrument in instrumental teaching for it can show students different musical field apart from piano and constantly expand students' vision and musical cognition so as to greatly enrich students' knowledge scope and constantly increase students' musical quality and motivating their musical talents.

(2) Effective promotion for students' musical abilities. Firstly, since learning cellos have higher requirements for voice and harmony ability and rhythmic sense, students can realize the fully learning for these requirements during learning. Secondly, cello teaching requires students have strong expressiveness, so students can experience all the teaching factors for relevant musical emotions and styles during cello learning so as to increase their own emotional factors and emotional expressiveness. Thirdly, by the learning for cello courses and increases for extracurricular practices, students can have a comprehensive understanding for the relevant musical historical knowledge, culture connotations and music works structures of cello so as to constantly promote their own musical connotations and musical quality and promote the increase of their own comprehensive quality. Finally, during playing cellos, it requires the harmony and coordination of five sense organs and the operation of brains; and the effective combination of these two factors can effectively promote the harmony development of students and effectively promote the observation, imagination and memory of students.

(3) Cultivation of teamwork spirit for students. During the rehearsal and performance of cello, it has high requirements for the coordination and teamwork spirits between students. During the ensemble, cello requires the coordination of the comprehensiveness of band and perfect harmonization between their voice and other instruments; and special attention should paid to the volume, intonation and breath in performance techniques and the mutual coordination should be paid during the performance so as to have a effective cognition for the comprehensiveness of thoughts. In current stage, affected by Chinese traditional teaching system, schools pay more attention to the teaching and promotion of students' own quality during teaching, which would ignore the cultivation of teamwork spirit to some extent. Therefore, higher normal colleges can effectively promote students' teamwork spirit during cello teaching and constantly promote the music teaching of China in the future.

\section{Status quo and research on the cello teaching in higher normal colleges at present}

Backward teaching concept and much attention on teaching techniques. Affected by traditional Chinese teaching concept, Chinese higher normal colleges do not pay much attention of cello teaching and do not emphasize the teachers for cello teaching and construction of software and hardware environment. Meanwhile, there is lack of relevant complete research on the specialized cello teaching in Chinese educational fields. Therefore, during the cello teaching in Chinese higher normal colleges, it still follows the teaching methods and teaching systems specialized musical colleges and more attention is paid the performance techniques of cello while the teaching modes still follow the one-to-one teaching in music colleges. Due to the over-emphasis on technique teaching for cellos in higher normal colleges, teachers would spend much time for the teaching and improvement of performance skills of students based on requirement and regularly test students' skills. Though this method can promote professional skills etc, the stereotype teaching mode would severely affect the learning interests for cello to some extent and affect their sensational ability for music. Students spend much time in the improvement and promotion of cello and lacks of the deep cognition and understanding of the connotation of cello works. The long term application of this mode would gradually make students lack of control for works so as to not be able to fully represent the connotations and emotions of works and lack of emotional infection.

Monotonous curriculum setting and lack of relativity of courses. At present, the curriculum setting for cello teaching in China does not pay attention to the individualistic of students. Most students in higher normal colleges are not professional students and there are many differences in 
students' fundamental ability. However, the current cello teaching in China does not set different courses for the individuals of students and all the students are unified taught; therefore, there is polarized teaching effect, which is bad for the promotion of fundamental instrument ability. With the constant setting of cello majors in higher normal colleges, there is a phenomenon of comparison between students in higher normal college and professional music major students. The learning for cello courses and skills resulted from the unreasonable curriculum setting cannot satisfy the social requirements of modern society, which is not suitable for the development of students. During the current cello teaching in higher normal colleges, the cello teaching is often isolated from the musical teaching. Therefore, for professional cello students, it often ignores the musical teaching during professional teaching, which leads to illusion for musical learning and is bad for the promotion of their own musical quality.

Lack of pertinence in textbook. The major quality for cello teaching in higher normal colleges is different. And there is difference in the teaching contents and teaching objectives for cellos in higher normal colleges and professional music colleges, which has special requirements for textbook. Nowadays, there is no special professional textbook for cello teaching in higher normal colleges. Currently, the cello teaching textbook in higher normal college is from the music colleges or amateur grade test whose content settings and schedule cannot satisfy the teaching requirements for cello in Chinese normal colleges, which is bad for the development of teaching activity.

\section{Reforms and measures in cello teaching of higher normal colleges}

Chinese educational ministry requires the educational aims for the music in higher normal colleges based on the current teaching requirements, and it should pay attention to the students' musical fundamental theoretical knowledge and cultivation of basic musical skills as well as to relevant music practical teaching and promote the cultivation of future teachers' quality so as to make it have stronger practical ability and creative ability so as to constantly promote the comprehensive development of students and effectively adapt to the requirements of future and modern educational as well as promote the reform and teaching development of their own educational concept.

More attention on teacher's construction and promotion of teachers' expertise of music. As for the teaching of cello teachers in higher normal colleges, colleges should set up cello elective courses during the postgraduate teaching so that students can selectively learn cello according to their interests, which can expand the student's employment channels and cultivate qualified cello teachers for the higher normal college itself so as to reduce teacher's construction costs. Higher normal colleges can set up postgraduate courses for cello teachers based on their own demands so that students majoring in cello can further their postgraduate after finishing bachelor learning. Colleges should also enhance the academic and skills communication between the cello teachers so also to constantly promote the teaching skills innovation and compensate for inefficiency.

Refining curriculum setting and attention on individualized teaching. The educational objective for music in higher normal college is to cultivate future music teachers. Therefore, the curriculum setting for cello majors should not only consider the expertise but also coordinate the relation between expertise and teaching so as to cultivate the students' expertise and improve students' teaching ability. So colleges should make their own learning objectives based on the students' professional ability based on the teaching methods of professional music colleges during the curriculum setting. Based on the technical requirement, it should emphasize the normative and increase students' stage expressiveness and expand their choice of employment. Teachers should make individualized teaching methods for a few students who are excellent in techniques and theories. As for some students with good fundamental knowledge, students often work as basic music teachers after the colleges. Therefore, during teaching, teachers should emphasize the fundamental training of students and involve different styles in teaching to expand the music learning contents.

Attention on the edition of professional textbook for higher normal colleges. During the cello teaching in higher normal colleges, elective students for cellos often have no fundamental 
knowledge. Under this condition, higher normal college teachers should pay attention to the interestingness of textbook. And the content of textbook is mainly composition to properly reduce the exercise and increase practical music. As for the teaching orientation in higher normal college, it can properly increase the teaching methods and contents for organizing bands during the edition of cello textbooks; therefore, students can have relevant teaching and rehearsing ability and attention should be paid on technical training to enhance position competitiveness.

\section{Conclusion}

In a word, affected by Chinese traditional teaching modes, the cello teaching in Chinese normal college is backward and has other problems, including over-emphasis on teaching techniques, single courses setting, and lack of pertinence of course, lack of pertinence in textbook. Therefore, higher normal colleges should promote their own teachers construction, refine the courses setting, emphasize the edition of professional textbooks for higher normal colleges and constantly promote the cello teaching quality.

\section{References}

[1] F.M. Lou. Exploration on cello teaching in higher normal colleges. Northern Music, 2014, 01:123-124.

[2] F.M. Lou. Plans for the cello teaching reforms in higher normal colleges. Journal of Chifeng Institute (Natural Science Edition), 2014, 15:210-211.

[3] X. Wang. Research on the cello teaching in the music education in higher normal colleges. Guangxi Normal University, 2012.

[4] T. Ning. Analysis on several problems for cello teaching in ordinary colleges [D].Shanghai Conservatory of Music, 2013.

[5] H.Y. Xu. Permeation of instrumental elective courses with relevant disciplines in higher normal colleges --Take cello as an example. Master, 2011, 18:96. 